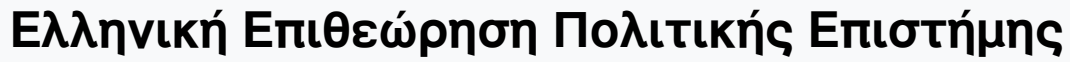

Tó 4.42 (2014)

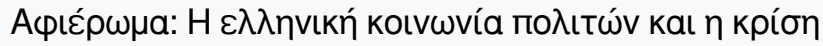

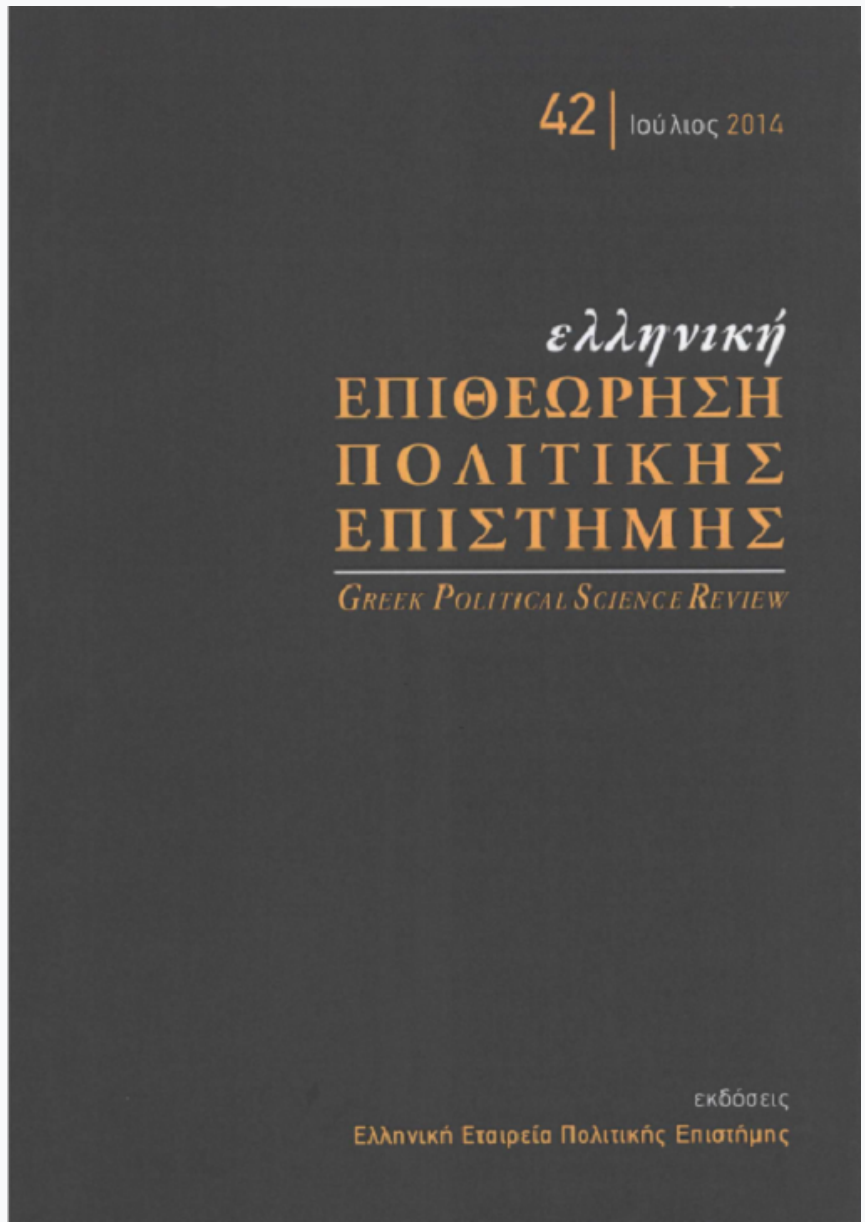

NGOs and the Blogs: Greek civil society's role in a time of crisis

Mariangela Veikou

doi: $\underline{10.12681 / \mathrm{hpsa} .14571}$

Copyright $\odot$ 2017, Mariangela Veikou

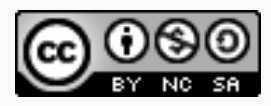

Ađ¿ıı Xpńбnৎ Creative Commons Attribution-NonCommercial-ShareAlike 4.0.

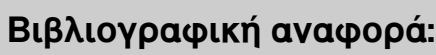

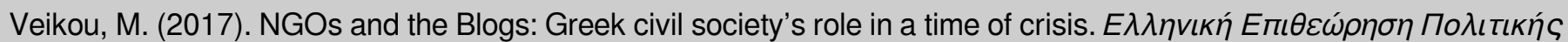

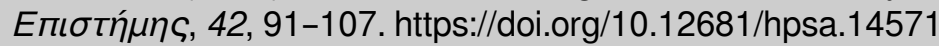




\section{NGOS AND THE BLOGS: GREEK CIVIL SOCIETY'S ROLE IN A TIME OF CRISIS} Mariangela Veikou ${ }^{*}$

This paper deals with the role of Greek NGOs in the field of migration today, as portrayed by new media platforms (blogosphere). The article identifies main lines of NGOs action as seen in the agenda of blogs which reflect issues that come to the fore with a focus on resource competition, social impact and values in a Greek society greatly hit by the crisis with consequences that impact the Greek civil society as a whole. ${ }^{1}$

\section{INTRODUCTION}

Immigration has been one of the most pressing challenges for Greek society in recent years and the responsibility for migrant welfare / integration has rested to an extent with NGOs in the country since the mid1990s. The deficit of Greek migrant integration policies is unavoidably a side effect of the poor general state of this South European country. It is, however, also closely linked to the low profile that NGOs have kept over several years for various different reasons. Despite the fact that during crisis, there is often an outburst of social and political mobilization, usually reflected in increased participation in voluntary associations, non-

* Mariangela Veikou is a post doctoral research associate at the department of Politics and International Relations of University of Leicester.

1. This research has been co-financed by the European Union (European Social Fund, ESF) and Greek national funds through the Operational Program "Education and Lifelong Learning" of the National Strategic Reference Framework (NSRF) Research Funding Program: THALES. Investing in knowledge society through the European Social Fund. 
governmental organizations and social movements, ${ }^{2}$ in Greece, research shows that especially since the crisis Greeks have gradually lost interest in politics and that civil society in contemporary Greece has always been weak. ${ }^{3}$ Participation in civil society ${ }^{4}$ has comparatively remained relatively low (see Table 1).

TABLE 1

PERCENTAGE OF POPULATION PARTICIPATING IN AN ASSOCIATION OR IN AN ORGANIZED VOLUNTARY ACTIVITY IN 12 EU MEMBER-STATES 2004

\section{COUNTRY}

\begin{tabular}{ll}
\hline Belgium & 46 \\
\hline Denmark & 84 \\
\hline Germany & 53 \\
\hline GREECE & 24 \\
\hline Spain & 28 \\
\hline France & 40 \\
\hline Ireland & 51 \\
\hline
\end{tabular}

COUNTRY

\begin{tabular}{ll}
\hline Italy & 34 \\
\hline Luxembourg & 57 \\
\hline Netherlands & 79 \\
\hline Portugal & 26 \\
\hline U.K. & 53 \\
\hline EU-12 average & $\mathbf{4 8}$ \\
\hline
\end{tabular}

Source: Eurobarometre, May 2004; for the 12 current Member States

2. P.C. Schmitter, “An Introduction to South European Transitions from Authoritarian Rule: Greece, Portugal, Spain, and Turkey”, in P.C. Schmitter -G. O' Donnel - L.C. Whitehead, eds., Transition from Authoritarian Rule: Southern Europe, The Johns Hopkins University Press, Baltimore 1986, pp. 3-10.

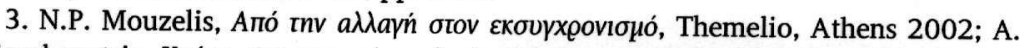

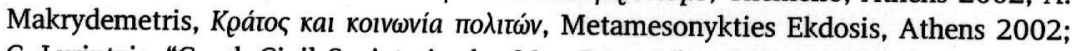
C. Lyrintzis, "Greek Civil Society in the 21st Century", in P.C. Ioakimidis, ed., Greece in the European Union: The New Role and the New Agenda, Ministry of Press and Mass Media, Athens 2002.

4. We accept an understanding of the concept "civil society" according to Mary Kaldor's activist definition; as she writes, "civil society refers to active citizenship, to growing self-organization outside formal political circles, and expanded space in which individuals can influence the conditions in which they live through political pressure" (M. Kaldor, Global Civil Society: An Answer to War, Polity Press, Cambridge 2003, p. 8). 
These conditions have not contributed to a rise in public awareness about the issue of immigration or to an exercise of effective pressure upon the state mechanism so that the latter lives up to its responsibilities vis-à-vis migration and the relevant action in need of effective solutions.

At this point it may be useful to include a quick note on the conditions currently shaping the approach to migration in Greece. Migration in Greece is typically seen as characterized by a low-scale and inefficient legislative framework, which has brought about a situation in which immigrants become integrated into a deregulated, informal economy, and a weak civil society with stakeholders and operators such as migrant associations and specialized NGOs striving to be included in the dialogue on migration policies and legislation, whereas the public consultation process is almost non-existent. ${ }^{5}$ However it is worth mentioning that in recent years we have seen a kind of public consultation, with the proliferation of people's opinions as embedded in new technologies, such as the Web 2.0 applications (i.e. blogs, social media, etc. ). Within this context, this paper will look at the contribution of blogging in terms of assessing the role of Greek civil society and in particular the role of specialized NGOs regarding the migration issue.

Specifically, this paper focuses on certain kind of blogs, the political and / or activist ones, Greek or English written, and attempts to examine the picture these blogs provide of the role of grassroots organizations and NGOs in today's Greek society under crisis. In doing so, this paper begins with a review of the literature on blogs regarding their potential to provide an open environment that extends and reframes ongoing (online) debate and practices. Further, it reviews the structure of the Greek blogosphere ${ }^{6}$

5. M. Pavlou - I. Avramopoulou - L. Karakatsanis, “Greece”, in J. Niessen - Y. Schibel - C. Thompson (eds), Current Immigration Debates in Europe: A Publication of the European Migration Dialogue, Migration Policy Group, Brussels 2005.

6 . The term "blogosphere" has arisen to characterize the grassroots and interactive writing made possible by participants in blogs. Some writers call the millions of blogs and their contributors and users to a blog biosphere or ecosystem of the blogging community. For a brief history of the term, see J. Hiler, "Blogosphere: The emerging media ecosystem: How weblogs and journalists work together to report, filter and break the news", in Microcontent News, 2002, http://www. microcontentnews. com/ articles/blogsphere. htm. 
on the particular issue under study and presents the methodology followed to achieve the study's goals. The next section is concerned with the analysis of the material divided into clusters according to thematical orientation of the blog postings. In the concluding remarks the paper seeks to draw all the different threads of the analysis together and reach some conclusions regarding the implications of blogging in ways to enhance the influence and role of local civil society.

\section{EXPLORING THE MICRO-DYNAMICS OF GREEK BLOGOSPHERE}

There is little empirical research on the aspects of civil society in Greece. Relevant anthropological research and research in the sociology of networks is difficult to obtain, particularly for the case of contemporary Greece. Empirical research statements about the Greek civil society have been rare. ${ }^{7}$ Studies of particular sectors of civil society, such as organized interests, have been more numerous. ${ }^{8}$ For these reasons, we are unable to provide but only limited pieces of empirical data in order to make an assessment of civil society in Greece. Our assessment will be made on the basis of available data on the internet. We will present the existing few pieces of data, drawn on published sources in the web. More specifically, this paper looks at the role of NGOs, and Greek civil society in general, as seen by the new media (blogs in particular) because it acknowledges that the spread of new media has given rise to high expectations regarding their potential to democratize and open up spheres of public discussion not

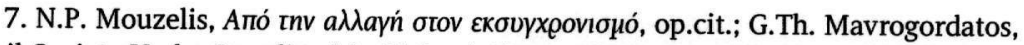
“Civil Society Under Populism" in Richard Clogg, ed., Greece, 1981-89: The Populist De-

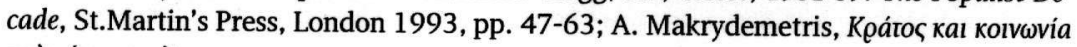
noגıı́viv, op.cit.

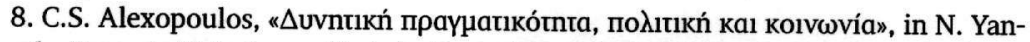

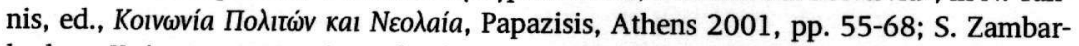

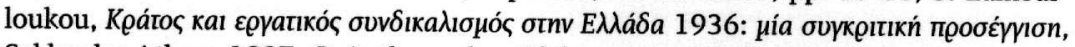

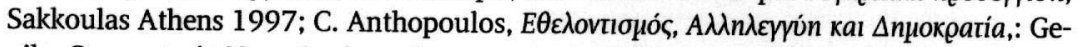
nike Grammateia Neas Genias Athens 2000; A. Huliaras - P. Sklias, eds., $H$

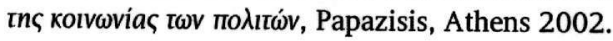


accessible before. Blogging is an activity that is potentially liberating in helping people to express themselves and open up which is, in turn, linked to freedom of expression and democracy. From this point of view, blogging is a politically relevant activity favoring not only democratic self-expression and networking, but also media critique and sociopolitical intervention. Researchers were quick to point out the ways in which blogging possesses a "social-transformative, democratizing potential" 9 by broadly creating a more liberal space for the articulation of views, especially those views (alternative and / or activist) that may be repressed in offline contexts. At the same time, in a political context, blogs, via the proliferation of discourses, shift the centre of power and influence by criticizing and often bypassing official structures and debates. ${ }^{10}$ They provide an environment that extends and reframes practices, such as criticism, which can often be disruptive but overall can also be seen in a positive light. Although we cannot report any measurable and tangible political gains in the proliferation of discourses, brought about by blogs, it may be argued that they have created new opportunities for openness, for debate and criticism, which will hopefully be followed by political change.

There is strong evidence that readership elites, i.e. opinion commentators, editors, publishers, reporters, columnists and academics consume political blogs. ${ }^{11}$ Because opinion makers, in the broader sense, take blogs seriously, the latter can have a wider impact on a more open democratic debate. Blogs possess a number of advantages in order to break open a plethora of views: Firstly, one advantage is the network ties between new media outlets and blogs. That blogs are linked together in a network provides much of their specific character (i.e. blogs interact with each other continuously, linking back and forth, disseminating arguments and

9. S.C. Herring - L.A. Scheidt - S. Bonus - E. Wright, "Bridging the gap: a Genre Analysis of Weblogs", in Proceedings of the 37th Annual Hawaii International Conference on System Sciences, Hawaii 2004, p. 1-11.

10. Cf. J. Graf, The Audience for Political Blogs. New Research on Blog Readership, Institute for Politics, Democracy and the Internet, Washington, DC 2006; C. Darr \& J. Graf, eds, Polinfluentials: The New Political Kingmakers, Institute for Politics, Democracy and the Internet, Washington, DC. 2007.

11. R. Smolkin, "The expanding blogosphere", American Journalism Review, vol. 14, 2004, pp. 100-111. 
points of view). The blogosphere being a networked phenomenon has important consequences also for how it may be studied. Blogs and the hyperlinks between them are amenable to analysis; By studying the network of blogs, the number of links to a particular blog, we may come to important conclusions about how (political) blogs can have a direct impact to the wider debate, a fact which is not evident in the offline practice of politics or media.

Secondly, blogs have the advantage of speedy formulation of opinions and publication of current events. Immediately following a current political issue bloggers have the ability to post their instant reactions before other forms of media can respond. Beyond initial reactions, bloggers can also respond to other blog reactions before the mainstream media has time to react. Richard Seymour, an Irish leftish blogger, best known for writing Lenin's Tomb, a political blog which features current affairs, exhibits in his writings the virtue of speed in blogging in that you can post something and provoke a quick response and a counter response fast enough to have real-world consequences. Beckett ${ }^{12}$ observes that the real value of searching the blogs is that you get a live picture of what people are thinking about certain issues. It means that you can predict if there is going to be an issue that is going to grow and become something you need to respond to before it becomes mainstream. The rapidity of blogger interactions and agenda setting affects political communication in mainstream opinion. The agenda-setting power of blogs is clear, if a critical number of elite blogs concentrate their attention on a breaking story or an underreported story it may pique the interest of mainstream readership and may create focal points for general interest. ${ }^{13}$ In that sense, the blogosphere has potentially the collective ability to act as a leading indicator of future political debate.

Thirdly, the blogs have the advantage of local knowledge or sometimes policy expertise that some bloggers possess and with that knowledge and expertise blogs usually play up stories from a perspective ignored by mainstream media outlets. These three advantages, taken together, provide an explanation as to how blogs may provide evidence

12. C. Beckett, "The Impact of blogging on domestic and international politics: Networked Journalism", in E-International Relations, 2008.

13. Op. cit. 
about the general state of opinion in the media and may have a wider impact on the public debate.

Fortunately for political scientists, blogs provide a uniquely rich set of data that can be exploited in order to explore a variety of research questions. In two research projects, Zafiropoulos \& Vrana ${ }^{14}$ and Karampasis ${ }^{15}$ provided a network map of the Greek blogosphere. They used technorati and mpouligator aggregators to track Greek blogs and provide indicators of their popularity and interconnections. They reported the existence of about 1.367 bloggers during 2002-3 with blogging expanding in Greece and in the next years reaching a number about 9.510 (4.639 of which active) in 2007 whereas later in 2008 reaching up to 26.573 (8.899 of which active) and counting. There exist about 9.510 blogs written in Greek (4.639 active). They went on to hand-code various blogs and reported their findings in terms of the various categories that developed, classified on the basis of their themes and general outlook. The larger percentage of blogs concerned personal interests, art and culture, entertainment and the like, whereas smaller categories gravitate around news, politics, media and the community. Blogs were divided into English and Greek-speaking ones, with the former more likely to advocate political issues and human and civil rights.

The arguments made in this paper are based on a qualitative analysis of content derived from a random sample of a variety of blogs, selected mostly by blogrolls ${ }^{16}$, (and only partly from data by structured interviews with NGO representatives and civil society actors and representatives of public benefit foundations). The research was conducted from April 2013 to January 2014. Most bloggers into our sample are avid consumers and creators of online content, evidenced by how often their blogs are updated, they keep well-publicized blogs which focus on politics. They view blogging as a public endeavor. Mostly they blog under a pseudonym or anonymously, while a good number of them blog under their

14. K. Zafiropoulos -V. Vrana, “A Social Networking Exploration of Political Blogging in Greece", in Emerging Technologies and Information Systems for the Knowledge Society, Springer, Berlin-Heidelberg 2008, pp. 573-582.

15. Z. Karampasis, "Blogging in Greece", 2007, http://ereuna.wordpress.com/

16. Part of the anatomy of a blog; a list of other blogs or websites that a blogger endorses or is affiliated with, which can be used to increase traffic to blogs and to ascertain readership. 
own name. We look at how bloggers approach the issue at hand and we focused on points of conflict in opinions in blog posts. We would like to note that the findings of this study are indicative, our sample was based on a variety of political blogsites. We have tried to minimize the risk of sample bias by reaching out to both highly linked and less highly linked blogs, that were situated on both the left and right of the political spectrum. The number of blogs we looked at, despite being relatively small, nonetheless, they do provide an initial mapping of the relevant shape of the boundaries and content of political discourse and public opinion online regarding the issue at hand.

Seeking to map the micro-dynamics of the blogosphere of political commentary on the role of Greek specialized NGOs in migration, although is far too diverse to be fully described here, we would say that in general most posts aim to have a more localized impact, using entries as public sphere commentary, they have more empirical focus, they are less abstract and try to understand the role of the NGOs in broader terms rather at a macro-level. A further classification would produce two main kind of blogs on the basis of their purpose: blogging as alternative politics and blogging as activism. While we make an analytical distinction between these two types of blogs, these are not mutually exclusive, and many blogs move easily from one type to the other. Alternative politics blogs deploy internet in a democratic and emancipatory manner for newscritique, to become informed, to inform others, and to construct new social and political relations. The interest on alternative politics blogs is their potential as alternative gatekeepers of information and news to old school media. ${ }^{17}$ Walker ${ }^{18}$ called blogs "a soapbox" and highlighted their attractiveness for voicing alternative political messages. Domestic internet users who are determined to argue in public about the things that matter to them use blogs to command attention in topical issues and criticize political leaders, decisions and even comment broadly upon the political system. For example, over the last few years in Greece, a plethora of left-oriented blogs were created and organized themselves in

17. P. Pedley, "International phenomenon? Amateur journalism? Legal minefield? Why information professionals cannot afford to ignore weblogs", in Business Information Review, vol. 22, no.2, 2005, pp. 95-100.

18. J. Walker, "Weblog", Routledge Encyclopedia of Narrative Theory, Routledge 2007. 
networks of interlinking solidarity, so as to contest what is perceived to be a politically-domesticated forum of conservative opinion across the offline political spectrum (typically blogging has been explicitly political in commenting upon Golden Dawn). Many domestic political bloggers have demonstrated the ability to influence opinion making, locally and abroad, with their focus of attention upon the racist remarks and actions made by Golden Dawn and the brutal ways in which they are often repressing migrants.

On the other hand, activist blogs employ the internet to foster affiliations and stage events coordinate smart mobs ${ }^{19} 5$ and action, provide information and in general propagate a cause. Sometimes activist bloggers are associated with political movements and get involved in organizing protests and other political activities or they publicize information on human rights abuses and/or NGO corruption. Media scholar and internet activist Ethan Zuckerman ${ }^{20}$ recently gave a lecture entitled 'The Emergence of Digital Civics' explaining that activist blogs appear to play an increasingly important role as a forum of public action and debate, with knock-on consequences for the media and for politics. For example, the Occupy Movement in Greece and its associated bloggers, publicized protests, when the mass media offered no publicity, and coordinated protest action. Among others, they alerted the readers to the actions of a couple of NGOs which orchestrated the first planned occupation in Greece and in that way disproved the alleged disconnect between nongovernmental organizations and new, spontaneous, decentralized forms of civic activism.

Both alternative politics blogs and activist blogs are oriented towards domestic politics and despite their strong national orientation, these bloggers use English either exclusively or in addition to Greek, purposely addressing an international audience as well, by providing information, analysis and explanations regarding the Greek society. However, it is not clear to which extent these blogs are actually read by a domestic audience.

19. A large group of people mobilized by weblogs or social media to meet in a public place typically for the purpose of social or political protest.

20. E. Zuckerman, "The Emergence of Digital Civics Understanding digital civics", Flinders University, 2012 in CFCM, http://www.ethanzuckerman.com/blog/ 2012/08/30/understanding-digital-civics/\#sthash.Yllax9Yy.dpuf 
The key empirical research question of the paper is how the blogosphere in Greece depict the role of NGOs and grassroots organizations, active in the field of migration, on how the economic crisis has altered their mode of action, as well as their relations with state and civil society in general in the last decade. Before going into the analysis of the findings in the next section we will provide an overview of the specialized NGOs in question.

\section{GREEK NGOS AND MIGRATION}

The Greek NGO sector with a specific mandate to assist migrants is a relatively recent phenomenon. Many of the organizations were founded at the mid of the 1990s. A wide range of NGOs and grassroots organizations and collective bodies of the civil society active in the field of migration - still under development in Greece -aim at promoting migrants' legalization and integration into society, and their goals and activities incorporate relevant issues, depending on the type of NGO. Generally speaking Greek NGOs constitute a network which mainly fills up the gaps at the locally underdeveloped social protection institutions, concentrating human resources. NGOs are maintained at best on a semi-voluntary basis due to the lack of own funding, while funding mainly is derived from European funds and sources managed by Greek authorities. The lack of any integration strategy going hand in hand with a corresponding major economic downturn at the national level has contributed to a situation in which the NGO sector in Greece continually deal with emergencies. In the context of an emergency-based assistance 'policy', NGOs are struggling to meet at least some of the basic needs of the recently arrived. ${ }^{21}$ They provide shelter, usually available for up to three months, while they also offer free meals (one per day) to the poor in general (i.e. Food Bank, Mporoume, Praksis etc.), they additionally offer free Greek language courses for immigrants, including refugees. Some NGOs adopt

21. Greece is currently one of the main entry points to Europe for migrants. In the absence of legal entry paths, the majority of migrants arrive in Greece irregularly. Many see Greece as the passage to Western Europe, and therefore do not apply for asylum but remain undocumented in the country for several years. Some eventually leave the country, while others end up staying permanently. 
an all embracing approach and aim at promoting migrants' integration by organizing actions related to improving the legal framework, defending their rights and supporting them to organize socially their lives (i.e. the Network for the Social Support of Refugees and Migrants, Athens Voluntary Work, Red Cross, Caritas, the Lyceum of Greek Women, etc.). There are NGOs that inform and counsel migrants on their legal, human rights (i.e. Greek Council for Refugees, Metadrasis etc). by providing pro bono legal and social assistance to migrants and asylum seekers, especially to unaccompanied minors, certification to victims of torture and trafficking and assistance to voluntary return; There are other NGOs that are supporting migrants to establish their labour rights or they promote networking among migrant communities and employers, state agencies, etc., as well as acting as intermediaries in order to help migrants address public services (i.e. Pyxis Multicultural Centre, ARSIS etc.) and offer free assistance and information on matters relating to work, social insurance, residence, etc. A number of organizations provide free medical services to migrants (i.e. Medecins Sans Frontières, Medecins du Monde, Red Cross, the Greek Centre for Multicultural Psychiatric Care, etc.). All these types of assistance offered by the NGO sector are scarce, particularly accommodation. Moreover, other integration initiatives and often innovative programmes aimed at the employment and/or educational needs of migrants, set up by some NGOs, remain only small projects, inadequate to meet the needs of a growing migrant population in the country. This situation is only made worse by the lack of organizational and financial capacity of the NGO sector to provide sufficient assistance to migrants.

What is more, Greek society finds itself significantly transformed, undergoing a extreme transitional phase under the economic crisis which is affecting, among other things, the way the Greek civil society views itself. The kind of economic state of emergency in need of all sorts of austerity measures the Greek society is facing, shockingly, brings about the fear even in liberal minds that the country cannot provide for all. Being "in economic crisis" is a period of vulnerability and insecurity, being a migrant, all the more, under such circumstances is a condition of utter socio-economic marginalization. Temporary or permanent integration in this context, becomes a question of individual efforts. ${ }^{22}$ Greek 
reception structures do not seem to encourage permanent or temporary migrant settlement at the moment and the poor reception infrastructure that seems to exist runs by NGOs assistance and it is scarce, with few subsidies, no integration programs and no welfare provisions. In recent years, although the role of NGOs and grassroots organizations is publicly recognized, these organizations are seeking broader recognition through their participation in institutions of intervention, which have not yet been particularly developed in the Greek system of government.

\section{BLOGGING AND GREEK NGOS}

Various media platforms on occasion have been concerned with attempts to document the main activities of the most representative NGOs at the level of civil society in the area of migrants' rights in Greece, delivering information while initiating public dialogues which attempt to have an impact on the issue. Notwithstanding the working division of the Greek blogosphere between activist and political blogs in this study, many of the issues identified in common by bloggers as facing NGOs today concern the lack of funding, the rise of conservativism, the concerted battle on migration, high unemployment rates, the economic crisis, etc. which are all redefining the role of grassroots organizations. Regarding how new media and blogs in particular engage with the role of the NGOs, it is important to note that their instincts are mainly to be very critical of NGOs actions, although theoretically they are quite supportive of NGOs role in principle. To a considerable extent, many aspects of the picture painted at the Greek blogosphere and social media sites regarding the role of NGOs and the civil society in general are rather bleak.

Dividing the postings in thematic areas (clusters) by using various different tags, one of the main messages we find in a first cluster of blog postings warns that many well-established non-governmental organizations have become disconnected from people's aspirations and concerns

tions with Greeks and invisible recruitment in a well-established informal economy (R. King, "Southern Europe in the Changing Global Map of Migration", in R. King - G. Lazaridis - C. Tsardanidis, Eldorado or Fortress? Migration in Southern Europe, Macmillan, Basingstoke 2000. 
and they are at the verge of facing irrelevance. This reflects the perception of the lack of professional standards and 'best practices' in the field by the NGOs. Blogs alert that citizens are increasingly coming together in new and informal forms of association to affect social change in their own communities, often disregarding 'traditional' NGOs. A case in point are the increasing number of individuals using social media to connect with one another, even on activist social issues, while established organizations watch from the sidelines. Blogs emphatically note that civil society organizations must embrace people's movements to connect better with the public and renew themselves in their practices and their rhetoric in order to survive.

A second cluster of posts concerns Greek civil society, with blogs discussing the past five years (well into the midst of the economic crisis) actions of NGOs in a general scheme to track the political, institutional, social and cultural constraints faced by Greek civil society. The erosion of the political space for civil society as well as the effects of economic crisis in Greece is a well known reality that is silencing NGOs. To make matters worse, most NGOs are under the financial impact of the economic crisis on their organizations. This affects their capacity to outreach, mobilize, engage and advocate effectively. More specifically, within the last years blog posts are strongly characterized by intense criticism as to how NGOs have been handling their new adopted profile under the crisis. More than ever before, the NGOs in question are criticized that, as humanitarian organizations who control the distribution of aid, they regard themselves accountable to their donors (private initiative/state institutions) rather than to their beneficiaries (migrants/refugees). Because giving assistance is generally regarded as charity in Greece, NGOs assume the power to decide who is deserving aid. Seen from this perspective, they adopt a rhetoric, playing up the stereotype of the helpless migrants/refugees as one of the survival strategies used in the context of fierce competition over scarce humanitarian aid resources to be successful in obtaining funds. ${ }^{23}$ In today's Greek society, while images of the "good" migrant who is starv-

23. NGOs would have to review their current communication politics, as the continuing patronization of migrants contributes to the victimization and also degradation of this particular group, cf. S. Waldron, "Blaming the Refugee" in Refugee Issues, vol. 3, no. 3, 1987, pp. 1-19. 
ing and helpless may motivate people/private donors to become helpers, there is an alternative stereotype of "bad" migrants as "bogus", "fortune seekers" who are out to subvert the aid system and it is rather the latter image that has the greatest bearing on how migrants are treated. Neither image embodies the complexities of human migration and whether or not a particular migrant is likeable may not in itself be the basis of the articulation of his/her needs in terms of rights. Therefore, in a domestic climate intensified by the crisis, which perceives migrants as a threatening group within the host country, Greek NGOs appear in the blogosphere as adopting a defensive rhetoric, as if aiding and abetting a threat to society, playing the recurrent stereotypes against each other.

Mark Walkup argues that despite their numbers and diversity, NGOs display remarkable similarities in terms of their organizational culture, a culture which he describes as rigid and conservative, orchestrated by organizational survival. ${ }^{24} \mathrm{He}$ argues that on the one hand, they are self-characterized as benevolent and selfless organizations, while their "rational" interest in their own survival requires them to employ "the same strategies of competition for survival and growth in a market environment as are employed by most profit-making corporations". ${ }^{25}$ Interestingly unlike business corporations, NGOs are not threatened by the dissatisfaction of service by their clients (migrants), but by their donors, understandably, then, they are naturally more responsive to donor interests than to the needs of the affected population. ${ }^{26}$ Walkup's study of the organizational culture of humanitarian organizations provides a convincing theoretical explanation of the structure and the practice of Greek NGOs towards migrants as indeed reflected in the postings we read. As a consequence, many postings question the accountability of NGOs which according to them is skewed in the direction of the donors who pay for the assistance, rather than the migrants or the civil society, as such.

Furthermore, since NGOs are hardly able to negotiate with state institutions on an equal level for funding and participation in institutions

24. M. Walkup, "Policy dysfunction in humanitarian organizations: The role of coping strategies, institutions, and organizational culture", in Journal of Refugee Studies, vol. 10, no. 1, 1997, p. 50.

25. Op. cit., p. 58.

26. Op. cit. 
of intervention, they have to act as entrepreneurs to bring their agenda forward. This involves the framing of issues in a way that these become hard to refuse and are able to gain wider support. Often this is achieved either by building alliances with like-minded NGOs or by contract using 'blaming and shaming' techniques towards rival NGOs. The conditions of work that lead to the above symptoms are the impossibility (given the scale of the need) of significantly improving the conditions of affected people, insufficient budgets and resources to meet needs, not sufficient professional, adequately qualified, personnel, powerful ethical dilemmas arising from the contradictions between expectation and reality, etc. Such "political" forces at work by NGOs are the target of criticism in a third cluster of blogs which invites a heated and at times hostile commentary.

Although the growing mistrust and criticism directed against Greek NGOs based on accusations of self-interest, 'hidden' agendas and ineptitude may be well-founded, media are often characterized by patronizing generalizations and resounding clichés, typically grouping NGOs indiscriminately, ascribing to them negative features and unethical behaviors, which, in turn, have important consequences on initiatives undermined and volunteerism discredited. ${ }^{27}$ In fact, a handful of positive highlights in the action of specialized NGOs are promoted in a fourth cluster of blogs we looked at. Regarding NGOs initiatives, however random, to organize campaigns and sensitize the public towards migrant problems and acceptance of diversity within Greece, we find occasional appreciative postings noting the collaboration of NGOs with a progressive segment of media in an effort to additionally give voice to migrant themselves (i.e. the Migrant Forum together with the Refugee and Migrant Support Network, have been organizing the Anti-Racist Festival in Athens). Assisted by EU funding, public awareness campaigns about the situation of migrants in Greece and the need to take measures to combat racism and discrimination organized by Greek NGOs gained the spotlight allowing NGOs to gain visibility and play a potentially more decisive role in the effective support of the rights of the people they are catering. In terms of blogs agenda, these positive trends of NGO action are mainly assessed as a quite sudden

27. A. Huliaras, "Evaluation of the NGO Sector in Greece", Thalis Programme, 2012, in http://greekcivilsocietynetwork. wordpress.com. 
change in the landscape of an increasingly vocal civil society in Greece over the past 5-8 years, which has benefited greatly from EU sources of funding, a sort of consolidation of increased volunteer participation in the civic sphere, including initiatives undertaken by known artists, media people and a small number of intellectuals who take part as activists themselves.

To sum it up, this modest positive change in the new media coverage about NGOs fails however to gain prime time visibility as it appears that on the whole, NGOs are not seen at the forefront of pro-immigrant civic activism and this overall limited activity has to be seen also against the background of a rather weak local civil society.

\section{CONCLUSION}

This paper has attempted to present the role and image of Greek NGOs through postings at the politically alternative and activist blogosphere. This analysis is by no means an exhaustive study on blogging and the role of the Greek specialized NGOs on migration. Rather, using new media as a helpful research tool, it is a call to critically examine the character and effect of civil society in Greece and to serve to generate hypotheses to be tested in future empirical research. As the study reveals, political debates within the Greek blogosphere provide important evidence of what is relevant to current debates on civil society since political blogs are an increasingly pervasive tool. The blogs emphasize the need for the Greek regime on migration, state and NGOs alike, to be radically revamped and to be based on a clear, long-term policy in accordance with contemporary international and European standards. To this effect, blogs bring up a number of important questions, which ought to be taken seriously not only by NGOs but by anyone trying to affect social change in Greek civil society. In essence, blogs look at the nature of civic activism and mobilization in Greece today, they ask what types of social structures are most adequate to deliver the change that people in society aspire to and they provide actionable recommendations as to how to (re) build civil society in support of participatory and progressive change. The insights made public by new media can be helpful in a process of change. Greek NGOs may consider whether they could recognize and 
accept that these dynamics exist and how could they learn to cope with failure and institutional limitations in ways that do not resist initiatives and voluntarism. ${ }^{28}$

28. A list of selected blogs and web-sites includes: Athens Indymedia (http:// athens.indymedia.org/), TVXSS (http://tvxs.gr/news/all), Critical Legal Thinking Law and the Political (http:// criticallegalthinking.com/), Greek Left review (http:// greekleftreview.wordpress.com/), Alter Summit (http://altersummit2013.blogspot. gr/), Red Notebook (http://www.rednotebook.gr/), The Press Project (http://www. thepressproject.gr/), Transform European Network for Alternative Thinking and Political Dialogue (http://transform-network.net/blog/blog-2014.html), Telekommunisten (http://telekommunisten.net/), Greek Learning about Politics Blog (http:// learningaboutpolitics.eu/greeksite/), Keep talking Greece blog (http://www.keeptalkinggreece. com/), Anarchist Memes (@AnarchistMemes), Jungle-Report (jungle-report. blogspot.com/), Internetocracy (@Internetocracy), Activist Posts (@ActivistPost). Lifo Blogs (http://www.lifo.gr/lifoblogs/blogs), Iefimerida (www.ifimerida.gr), Psi-action (http://psi-action.blogspot.gr/), Humanitarian and Development NGO Domain (http://hausercenter.org/iha/about-2/), Media and social change blog, Demos (http://www.demos.co.uk/blog), Media/anthropology blog, Lenin's Tomb (http:// www.leninology.com/), Guardian, Comment is free (http://www.theguardian.com/ commentisfree/2013/ sep/24/golden-dawn-greece-state-authority). 